\title{
Necessity of dietary lecithin and eicosapentaenoic acid for growth, survival, stress resistance and lipoprotein formation in gilthead sea bream Sparus aurata
}

\author{
Jingle LIU, ${ }^{1}$ Maria José CABALLERO, ${ }^{2}$ Marisol IZQUIERDO, ${ }^{2, *}$ TAMER EL-SAYED ALI, ${ }^{3}$ \\ CARMEN MARÍA HERNÁNDEZ-CRUZ,2 ANTONIO VALENCIA² AND \\ HipóLITo FERNÁNDEZ-PALACIOS ${ }^{2}$ \\ ${ }^{1}$ Institute of Oceanology Academia Sinica, Quingdao 266071, People's Republic of China, \\ ${ }^{2}$ Grupo de Investigación en Acuicultura, Islas Canarias, Spain and ${ }^{3}$ Oceanography Department, \\ Faculty of Science, Alexandria University, Alexandria, Egypt
}

\begin{abstract}
The substitution of dietary docosahexaenoic acid (DHA) with eicosapentaenoic acid (EPA) reduces larval growth in gilthead sea bream. However, the value of EPA when dietary DHA is able to meet the requirements of the larvae has not been sufficiently studied. Dietary phosphoacylgliceride levels also affect fish growth and it has been suggested that they enhance lipid transport in developing larvae. The present experiment was carried out to further study the effect of dietary lecithin and eicosapentaenoic acid on growth, survival, stress resistance, larval fatty acid composition and lipid transport, when DHA is present in the microdiets of gilthead sea bream. Eighteen thousand gilthead sea bream larvae of $4.99 \pm 0.53 \mathrm{~mm}$ total length were fed three microdiets tested by triplicate: a control diet [ $2 \%$ soybean lecithin (SBL) and $2.89 \%$ EPA], a low EPA diet ( $2 \%$ SBL and $1.63 \%$ EPA) and a no SBL diet (0\% SBL and $2.71 \%$ EPA). Handling, temperature and salinity tests determined larval resistance to stress. The results show that when dietary DHA levels are high, but dietary arachidonic acid (ARA) levels are about $0.2 \%$, EPA is necessary to improve larval growth, and survival. Larval EPA content, but not DHA or ARA, was affected by dietary EPA levels. Increased dietary EPA improved larval stress resistance to handling and temperature tests, which could be related to its possible role as a regulator of cortisol production, whereas it did not affect stress resistance after salinity shock. Larvae fed the no SBL diet showed a lower lipid content characterized by a low proportion of saturated and monounsaturated fatty acids, together with a significant reduction in the appearance of lipoprotein particles in the lamina propria and in the size of such particles, denoting a critical reduction in dietary lipid transport and utilization, and lower larval growth and survival rates.
\end{abstract}

KEY WORDS: essential fatty acids, fish larvae, lipid transport, lipids, lipoproteins, phospholipids, soybean lecithin, stress resistance.

\section{INTRODUCTION}

Larval rearing success is greatly influenced by first feeding regimens and the nutritional quality of starter diets. Although at present most marine fish larvae are fed live prey, such as, rotifers and Artemia, great effort has gone into the development of inert diets that would be able to sustain high larval growth and survival rates. Dietary lipids are recognized as one of the most important nutritional factors affecting larval growth and survival. ${ }^{1}$ However, dietary lipid utilization and lipid transport seems to be delayed in marine fish larvae fed

\footnotetext{
*Corresponding author: Tel: 34-928-132-900.

Fax: 34-928-132-908. Email: marisoli@iccm.rcanaria.es Received 25 June 2001. Accepted 8 April 2002.
}

certain types of inert diets. It has been suggested that diets with a low content of phosphoacylgliceride (PL) reduce lipid transport from enterocytes to hepatocytes in larvae. ${ }^{2-4}$ Feeding larval gilthead sea bream diets without lecithin supplementation causes the accumulation of lipid vacuoles in the basal zone of the enterocyte and steatosis in the hepatic tissue. ${ }^{4,5}$ However, such lipid accumulation both in the liver and gut is markedly reduced by a $2 \%$ addition of soybean lecithin, which enhances the lipid transport activity in both organs. ${ }^{5,4}$ Kanazawa et al. have also postulated that fish larvae have a limited ability to synthesize phospholipids to form lipoproteins and consequently require the presence of dietary phospholipids to provide these serum carriers during rapid growth periods, such as, larval develop- 
ment. ${ }^{6,7}$ Besides, the ability of dietary n-3 highly unsaturated fatty acids (HUFA) with 20 or more carbon atoms and three or more double bonds to enhance lipid transport has also been suggested by other authors. ${ }^{4,8}$ But until now, the effect of both nutrients on lipoprotein formation in the larval gut has not been studied in detail.

The importance of docosahexaenoic acid (DHA) as an essential fatty acid for marine fish larvae has been pointed out in previous reports. ${ }^{9-12}$ Eicosapentaenoic acid (EPA) has also been shown to be essential when DHA was absent from the diet, and it has important functions in larval lipid metabolism. ${ }^{11}$ The substitution of dietary DHA with EPA significantly reduces larval growth in gilthead sea bream, however, the value of EPA when dietary DHA is able to meet the DHA requirements of the larvae has not been sufficiently studied. ${ }^{13}$

The aim of the present experiment was to further study the effect of dietary lecithin and eicosapentaenoic acid on growth, survival, stress resistance, larval fatty acid composition and lipoprotein formation, when DHA is present in the microdiets of larvae.

\section{MATERIALS AND METHODS}

Eighteen thousand 18-day-old commercially produced gilthead sea bream larvae $(4.99 \pm 0.53 \mathrm{~mm}$ total length, mean \pm SD; 0.03 mg dry body weight) were randomly distributed in nine fiberglass cylindrical tanks (2000 individuals per tank). Tanks, with a capacity of $100 \mathrm{~L}$, were provided with $50 \mathrm{~mm}$ mesh filtered seawater at a rate of 100 $125 \mathrm{~mL} / \mathrm{min}$, which flowed out through a $300 \mathrm{~mm}$ mesh to remove the non-ingested food. Water temperature $\left(18.8 \pm 0.3^{\circ} \mathrm{C}\right)$ and a photoperiod of $12 \mathrm{~h}$ artificial light were kept constant during the experimental period. No microalgae were added to the rearing tanks.

Three isoproteic and isocaloric diets were tested by triplicate (Table 1), all of them were based on whole squid meal, an ingredient with a good nutritional value and growth promoting factors in microdiets for gilthead sea bream. Since the importance of dietary lecithin in defatted squid meal based diets has been already emphasized in our former experiments, whole squid meal was used in the present experiment to test more practical diets and the importance of dietary lecithin when dietary polar lipids are not completely depleted. ${ }^{4,5,8}$ The first diet was a sardine oil based control diet containing $2 \%$ soybean lecithin $(60 \%$ polar lipids; Acofarma, Tarrasa, Barcelona, Spain;). The second diet was a low EPA diet where fish oil was substituted by oleic acid and DHA27 (Nippon
Table 1 Composition and analyzed lipid and protein content of the experimental microdiets (g/100 g of diet)

\begin{tabular}{lrrr}
\hline Ingredient & Control & Low EPA & No SBL \\
\hline Squid powder & 73.50 & 73.50 & 73.50 \\
Sardine oil* $^{*}$ & 6.27 & 0.00 & 6.27 \\
DHA oil $^{\dagger}$ & 0.00 & 1.69 & 0.00 \\
Oleic acid $^{\text {Soybean lecithin }}$ & 1.73 & 6.31 & 3.73 \\
Attractant $^{\ddagger}$ & 2.00 & 2.00 & 0.00 \\
Vitamin mixture $^{\S}$ & 3.00 & 3.00 & 3.00 \\
Mineral mixture $^{\S}$ & 6.00 & 6.00 & 6.00 \\
Gelatin & 4.50 & 4.50 & 4.50 \\
Lipid (\% dry basis) $_{\text {Polar lipids (\% dry basis) }}$ & 3.00 & 3.00 & 3.00 \\
Protein (\% dry basis) & 22.72 & 22.16 & 22.98 \\
& 62.61 & 8.43 & 7.10 \\
\hline
\end{tabular}

*Agramar SA, Spain.

${ }^{\dagger}$ Nippon Chemical Feed, Tokyo, Japan.

${ }^{\ddagger}$ Kanazawa etal. ${ }^{38}$

${ }^{\S}$ Kanazawa. ${ }^{39}$

"Teshima et al. ${ }^{40}$

DHA, docosahexaenoic acid; EPA, eicosapentaenoic acid; SBL, soybean lecithin.

Chemical Feed, Tokyo, Japan), an oil rich in docosahexaenoic acid (DHA) but lower in eicosapentaenoic acid (EPA) than fish oil. Finally, in the third diet, soybean lecithin was substituted by oleic acid. This was called the 'no SBL' diet. All ingredients were pulverized in a Cyclotec 1093 Sample Mill (Tecator, Hoganas, Sweden) because attractants and mineral mixtures may contain thick crystals. The ingredients were then mixed in a mortar and afterwards mixed with gelatin that had been dissolved in water at $80^{\circ} \mathrm{C}$. The paste was pelleted and dried in an oven at $40^{\circ} \mathrm{C}$ for $24 \mathrm{~h}$. The resulting pellets were ground in a miller (Cyclotec 1093 Sample Mill, Tecator) and sieved to obtain a particle size of $150-250 \mathrm{~mm}$.

Larvae were fed the experimental diets for 15 days at a rate of $2.0-4.5 \mathrm{~g} /$ day (based on our 12 years experience with microdiets for gilthead sea bream) by automatic feeders during the $12 \mathrm{~h}$ of light. Rotifers cultured on baker's yeast, were added to the tanks twice daily at $13: 00 \mathrm{~h}$ and at $17: 00 \mathrm{~h}$ to maintain a concentration of 3.5 individuals $/ \mathrm{mL}$ in the rearing tanks. The tanks were siphoned daily in order to keep them clean.

Larval growth was determined by measuring the total length of 30 larvae at the beginning (18-dayold larvae), middle (26-day-old larvae) and end of the experiment (33-day-old larvae) with a profile projector (Nikon V-12, Nikon Co., Tokyo, Japan). Larval survival was determined by manually counting all the live larvae at the end of the experiment. Larval resistance to stress was determined by three different tests that were carried out at the end of the experiment: 
1. Air exposure test: in this test larvae were held out of the water in a scoop net for $15 \mathrm{~s}$ and then moved to a $2 \mathrm{~L}$ tank provided with constant aeration. $^{14,15}$

2. Temperature test: in this test larvae were carefully removed with $1 \mathrm{~L}$ beakers from the main tanks where the water temperature was about $19.4^{\circ} \mathrm{C}$ to $5 \mathrm{~L}$ tanks where the water temperature was about $15^{\circ} \mathrm{C}$. The response to the stress was checked after $24 \mathrm{~h}$.

3. Salinity test: in this test larvae were carefully removed with $1 \mathrm{~L}$ beakers from the main tanks where the salinity was about $36 \%$ o to $2 \mathrm{~L}$ tanks with salinity of $46 \%$ o determined by a salinometer.

Twenty larvae from each tank were submitted to each test and their survival rate was determined after $24 \mathrm{~h}$.

At the end of the experimental period, all the remaining larvae and microdiets were deposited in plastic bags and stored at $-80^{\circ} \mathrm{C}$ until the analysis of proximal composition. Moisture and dietary protein contents were determined according to Association of Analytical Chemists (AOAC) methods and crude lipids were extracted as described previously by Folch et al. ${ }^{16,17}$ Fatty acids of methyl esters were obtained by transesterification with $1 \%$ sulfuric acid in methanol using heneicosaenoic acid ( $10 \%$ of total lipids) as an internal standard. ${ }^{18}$ The fatty acid methyl esters obtained were separated by gas chromatography (Shimadzu GC-14 a, Kyoto, Japan) run at the operating conditions described previously by Izquierdo et al., they were quantified by flame ionisation detectors (FID) and identified by comparison to well characterized external standards. ${ }^{19}$ Dietary polar lipids were separated by thin layer chromatography in S-II Chromarods (Iatron Laboratories, Tokyo, Japan), using methyl acetate: isopropanol:chloroform: methanol:0.25\% $\mathrm{KCl}(25: 25: 25: 10: 9)$ as a solvent system, and quantified by Iatroscan (Iatron Laboratories).

For the histological study 33-day-old larvae (10 larvae per tank) were anesthetized and fixed in $2.5 \%$ glutaraldehyde in $0.1 \mathrm{M}$ sodium cacodylate buffer (pH 7.2) containing $3.5 \%$ sucrosa at $4^{\circ} \mathrm{C}$. Afterwards, samples were rinsed in cacodylate buffer, postfixed in $2 \%$ osmium tetroxide in $1.5 \%$ potassium ferricyanide, contrasted in $1.5 \%$ uranyl acetate and dehydrated in ethanol and propylene oxide before embedding in Epon/Araldita. Semithin sections $(1 \mu \mathrm{m})$ were stained with toluidine blue. Ultrathin sections $(50 \mathrm{~nm})$ were contrasted with $2 \%$ lead citrate and observed in a JEOL 1200EX transmission electron microscope (JEOL USA, Peabody, MA, USA). Lipoprotein size and number of lipoprotein particles per unit area were calculated by counting and measuring these particles in 20 serial squares of $0.625 \mathrm{~mm}^{2}$ applied in the lamina propria and intercellular space among enterocytes of three larvae selected from each treatment.

Data were statistically analyzed with the softWare STATGRAPHICS PLU S for Windows 3.1 (Statistical Graphics Corp., Englewood Cliffs, NJ, USA) using one way analysis of variance (ANOVA) and the Tukey test $(P<0.05)$ for multiple comparison of means was applied. Data on survival rates, expressed as percentages, were normalized by the arcsine transformation and the Tukey test $(P<0.05)$ for multiple comparison of means applied.

\section{RESULTS}

Analysis of the fatty acid composition of the diets showed that the low EPA diet was characterized by lower saturated fatty acids and higher monounsaturated fatty acids, due to the replacement of fish oil by oleic acid and it also contained $45 \%$ less EPA than the control diet (Table 2). The no SBL diet was lower in n-6 fatty acids, particularly 18:2n-6, and higher in $18: 1 n-9$ than the control diet due to the substitution of the soybean lecithin by oleic acid.

Larval survival at day 32 after hatching was significantly lower in larvae fed diets with reduced amounts of either EPA or SBL (Table 3). Survival after stress resistance tests of larvae fed the no SBL diet did not significantly differ from the control (Table 3). However, survival rates of larvae fed the low EPA diet were lower, being significantly different from the control larvae when temperature shock was applied.

Larvae fed the low EPA diet showed a consistent reduction of growth that, at the end of the experiment, lead to significantly smaller larvae than those fed the control diet (Fig. 1). Feeding larvae with the no SBL diet resulted in a $32.55 \%$ reduction of larval average daily growth rates in comparison with larvae fed the control diet during the first 8 days of experiment and a $15.13 \%$ reduction during the last week. As a result, at the end of the experimental period the larvae fed the no SBL diet were significantly smaller than those fed the control diet (Fig. 1).

The initial fatty acid composition of the larvae was higher than the final fatty acid composition in the larvae in $18: 2 n-6$ and 18:3n-3 reflecting the previous feeding with Artemia nauplii (Table 4). Larvae fed the low EPA diet reflected the fatty acid composition of the diet showing higher monounsaturated fatty acid content (specially a $3 \%$ higher oleic acid), and lower n-3 fatty acid content (spe- 
Table 2 Fatty acid composition of the experimental diets (\% dry weight)

\begin{tabular}{|c|c|c|c|}
\hline Fatty acid & Control & Low EPA & No SBL \\
\hline $14: 0$ & 0.72 & 0.38 & 0.74 \\
\hline $15: 0$ & 0.08 & 0.08 & 0.08 \\
\hline $16: 0$ iso & 0.12 & 0.09 & 0.02 \\
\hline $16: 0$ & 4.33 & 3.62 & 4.26 \\
\hline $16: 1 n-7$ & 0.83 & 0.60 & 0.90 \\
\hline $16: 1 n-5$ & 0.03 & 0.03 & 0.03 \\
\hline $16: 2$ & 0.11 & 0.05 & 0.09 \\
\hline $17: 1$ & 0.15 & 0.16 & 0.18 \\
\hline $16: 4 n-1$ & 0.06 & 0.05 & 0.05 \\
\hline $16: 4 n-3$ & 0.16 & 0.01 & 0.13 \\
\hline $18: 0$ & 0.82 & 0.70 & 0.76 \\
\hline $18: 1 n-9$ & 3.51 & 6.69 & 5.10 \\
\hline 18:1n-7 & 0.00 & 0.00 & 0.06 \\
\hline $18: 1 n-5$ & 0.07 & 0.07 & 0.01 \\
\hline $18: 2 n-9$ & 0.03 & 0.04 & 0.04 \\
\hline $18: 2 n-6$ & 1.10 & 1.41 & 0.29 \\
\hline $18: 3 n-9$ & 0.04 & 0.05 & 0.04 \\
\hline $18: 3 n-6$ & 0.03 & 0.02 & 0.03 \\
\hline $18: 4 n-6$ & 0.04 & 0.02 & 0.03 \\
\hline $18: 3 n-3$ & 0.18 & 0.17 & 0.07 \\
\hline $18: 4 n-3$ & 0.21 & 0.06 & 0.19 \\
\hline $18: 4 n-1$ & 0.03 & 0.00 & 0.02 \\
\hline $20: 0$ & 0.04 & 0.02 & 0.03 \\
\hline $20: 1 n-9$ & 0.67 & 0.58 & 0.62 \\
\hline $20: 1 n-7$ & 0.00 & 0.00 & 0.02 \\
\hline $20: 2 n-9$ & 0.03 & 0.00 & 0.03 \\
\hline $20: 2 n-6$ & 0.04 & 0.03 & 0.03 \\
\hline $20: 3 n-6$ & 0.02 & 0.01 & 0.02 \\
\hline $20: 4 n-6$ & 0.22 & 0.17 & 0.20 \\
\hline $20: 3 n-3$ & 0.07 & 0.07 & 0.06 \\
\hline $20: 4 n-3$ & 0.07 & 0.06 & 0.07 \\
\hline $20: 5 n-3$ & 2.89 & 1.63 & 2.71 \\
\hline $22: 1 n-11$ & 0.16 & 0.10 & 0.10 \\
\hline $22: 1 n-9$ & 0.00 & 0.03 & 0.07 \\
\hline $22: 1 n-7$ & 0.00 & 0.04 & 0.04 \\
\hline $22: 3 n-6$ & 0.10 & 0.10 & 0.17 \\
\hline $22: 4 n-9$ & 0.00 & 0.00 & 0.07 \\
\hline $22: 4 n-6$ & 0.03 & 0.06 & 0.00 \\
\hline $22: 5 n-6$ & 0.07 & 0.11 & 0.17 \\
\hline $22: 4 n-3$ & 0.00 & 0.00 & 0.06 \\
\hline $22: 5 n-3$ & 0.19 & 0.12 & 0.25 \\
\hline $22: 6 n-3$ & 4.96 & 4.24 & 4.65 \\
\hline Saturated & 6.07 & 4.87 & 5.95 \\
\hline Monounsaturated & 5.27 & 8.15 & 6.94 \\
\hline$n-6$ & 1.65 & 1.94 & 0.94 \\
\hline$n-3$ & 8.73 & 6.38 & 8.21 \\
\hline n-3 HUFA & 8.18 & 6.13 & 7.82 \\
\hline DHA/EPA & 1.71 & 2.60 & 1.71 \\
\hline EPA/ARA & 13.39 & 9.62 & 13.53 \\
\hline
\end{tabular}

ARA, arachidonic acid; DHA, docosahexaenoic acid; EPA, eicosapentaenoic acid; HUFA, highly unsaturated fatty acids with 20 or more carbon atoms and three or more double bonds; SBL, soybean lecithin.

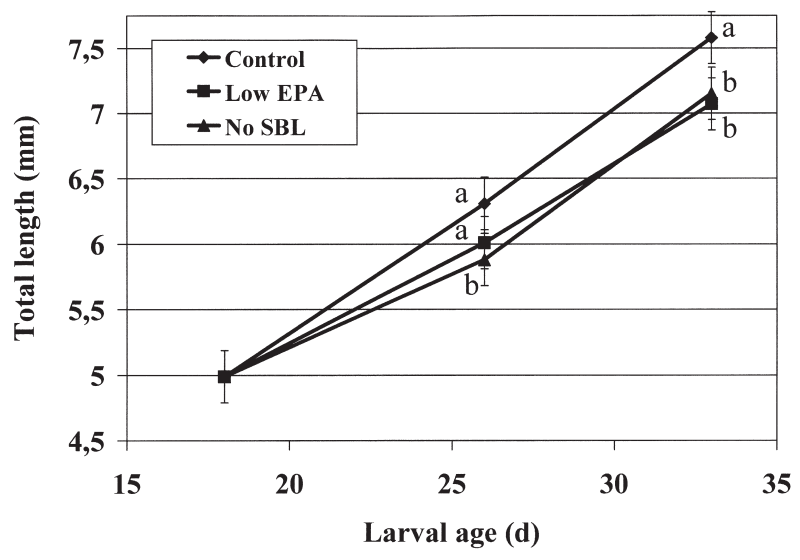

Fig. 1 Growth of larval gilthead sea bream along the feeding period.

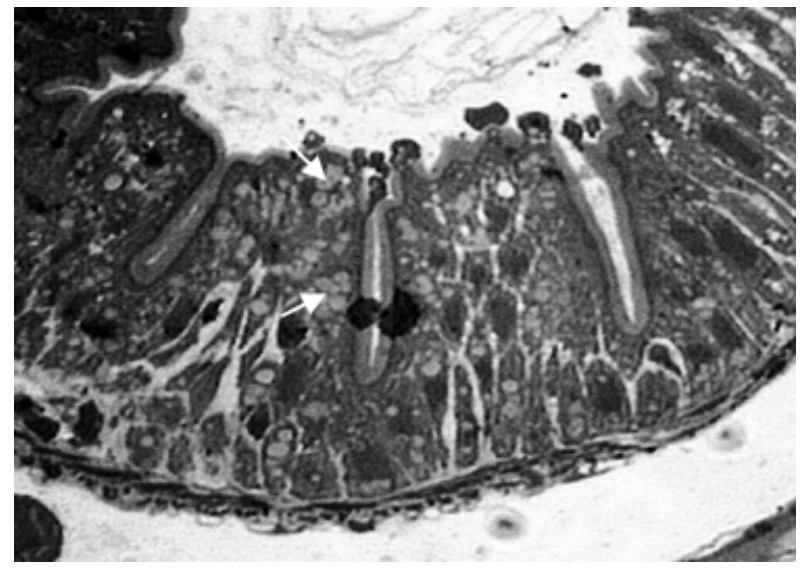

Fig. 2 Sagittal section of control larvae stained with toluidine blue $(\times 63)$. Lipid vacuoles (arrows) in the apical zone of enterocytes.

cially a $1.3 \%$ lower EPA) than larvae fed the control diet. Larvae fed the no SBL showed lower lipid content, lower saturated and n-6 fatty acid content and a relatively higher n-3 HUFA content than larvae fed the control diet.

In the anterior and middle region of the gut some lipid vacuoles located mainly in the apical part of enterocytes were observed for those larvae fed the control and low EPA diets (Fig. 2). Ultrastructural studies showed a lower presence of lipoprotein-like particles (mean LP size of 0.0816 $\mathrm{mm}, n=25$ ) in the lamina propria of gut from larvae fed the no SBL diet than in larvae fed either the control (mean LP size of $0.132 \mathrm{~mm}, n=50$ ) or EPA diet (mean LP size of $0.106 \mathrm{~mm}, n=50$; Figs 3-5). 
Table 3 Larval survival rate at the end of the experiment and after the three stress resistance tests of larvae exposed to different activity tests (20 fish $\times$ three tanks)

$\begin{array}{lcccc}\text { Diet } & \begin{array}{c}\text { Survival at day 32 } \\ (\text { mean } \pm \text { SE) }\end{array} & \begin{array}{c}\text { Air exposure } \\ (\text { mean } \pm \text { SE) }\end{array} & \begin{array}{c}\text { Temperature shock } \\ (\text { mean } \pm \text { SE) }\end{array} & \begin{array}{c}\text { Salinity shock } \\ (\text { mean } \pm \text { SE) }\end{array} \\ \text { Control } & 70.2 \pm 3.52^{\mathrm{a}} & 73.3 \pm 6.66^{\mathrm{a}} & 65.0 \pm 8.66^{\mathrm{a}} & 88.3 \pm 1.67^{\mathrm{a}} \\ \text { Low EPA } & 54.9 \pm 5.69^{\mathrm{b}} & 56.7 \pm 16.90^{\mathrm{a}} & 21.7 \pm 10.14^{\mathrm{b}} & 81.7 \pm 4.40^{\mathrm{a}} \\ \text { No SBL } & 54.4 \pm 1.45^{\mathrm{b}} & 71.7 \pm 8.82^{\mathrm{a}} & 63.3 \pm 4.40^{\mathrm{a}} & 83.3 \pm 9.28^{\mathrm{a}}\end{array}$

Values having the same superscripts in the same column are not significantly different $(P<0.05 ; n=3)$. EPA, eicosapentaenoic acid; SBL, soybean lecithin.

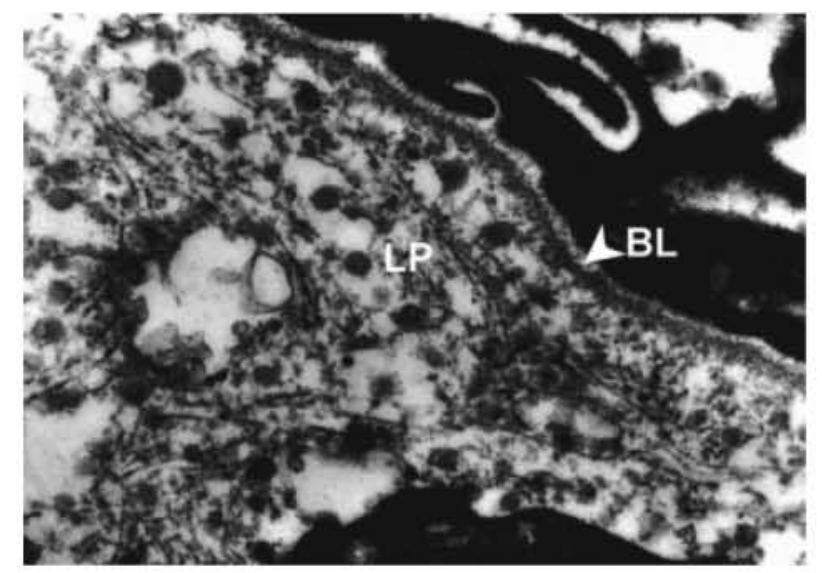

Fig. 3 Appearance of lipoprotein particles in the lamina propria of gut from larvae fed the control diet. LP, lipoprotein particles; BL, basal lamina $(\times 25000)$.

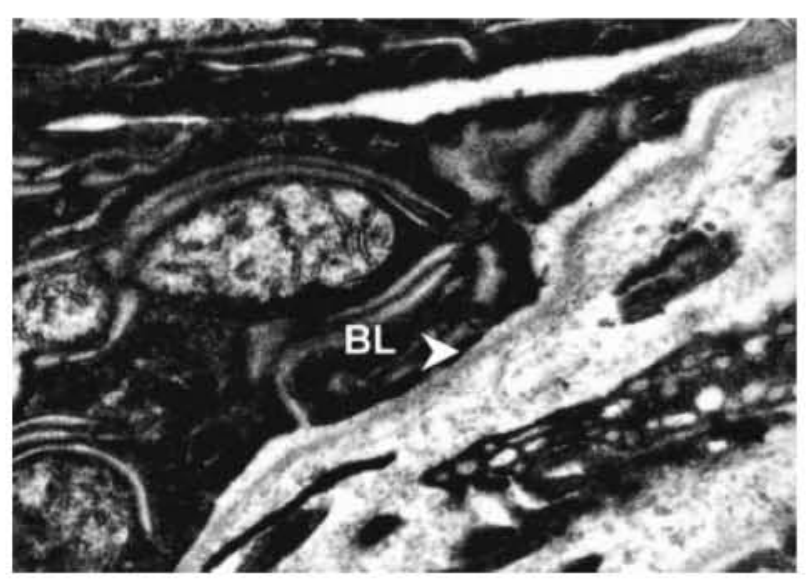

Fig. 4 Appearance of lipoprotein particles in the lamina propria of gut from larvae fed the no soybean lecithin (SBL) diet $(\times 20000)$.

\section{DISCUSSION}

Reduction of EPA dietary levels from 2.89 to 1.63 (\% dry weight) reduced larval survival, resistance to stress and growth, despite the presence of high

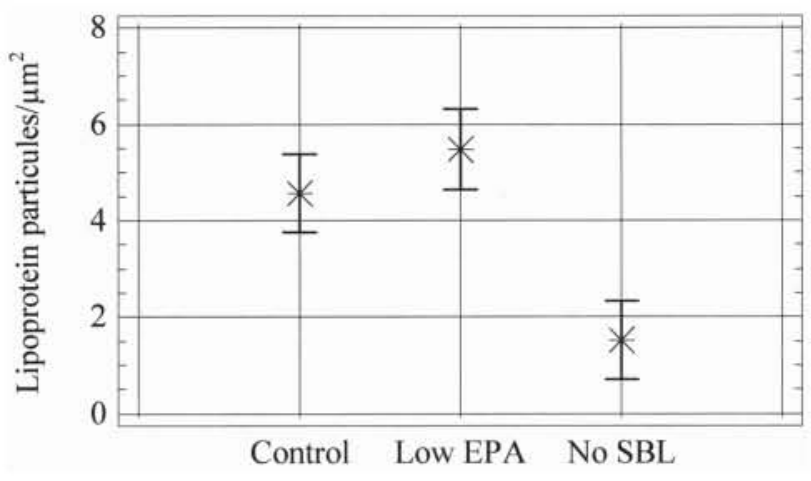

Fig. 5 Density of lipoprotein particles found in the lamina propria of gut in larvae fed the three different experimental diets.

dietary DHA. Eicosapentaenoic acid content was reduced in larval lipids. The incorporation of dietary DHA or arachidonic acid (ARA) into larval lipids was not affected by the dietary EPA levels. These results suggest the importance of the presence of EPA in larval lipids, at least when dietary ARA is low. Eicosapentaenoic acid has been shown to be essential for growth in the absence of dietary DHA in larvae of other sparids, flatfish and yellowtail. ${ }^{9,20,21}$ In the present experiment, EPA was also shown to be essential for gilthead sea bream in the presence of high dietary DHA levels. This has also been found in Japanese flounder. ${ }^{22}$ As a polyunsaturated fatty acid, EPA may be as important in the regulation of membrane fluidity and functions in fish as it has been shown to be in higher vertebrates. ${ }^{23}$ Thus, it contributes to the polyunsaturated fatty acid (PUFA) requirements of the larvae. For example, its presence in live prey enhances development of brain and eye. ${ }^{20,24}$ However, its value as a precursor of eicosanoids may partly cover the larval requirement for these compounds when dietary ARA is as low as in the present experiment $(0.20 \%)$. Its value as an essential fatty acid for gilthead sea bream when dietary ARA levels are high remains to be clarified. 
Table 4 Crude lipid content and fatty acid composition of total lipids from the initial larvae and larvae fed the experimental diets $(n=3)$

\begin{tabular}{|c|c|c|c|c|}
\hline Fatty acid* & Initial larvae & Control & Low EPA & No SBL \\
\hline 14:0 & 1.20 & 1.94 & 0.93 & 1.06 \\
\hline $16: 0$ iso & 0.00 & 0.00 & 0.09 & 0.00 \\
\hline $16: 0$ & 15.11 & 24.98 & 19.32 & 16.11 \\
\hline $16.1 n-9$ & 0.75 & 0.61 & 0.79 & 0.68 \\
\hline $16: 1 n-7$ & 6.88 & 6.27 & 7.02 & 6.59 \\
\hline $16: 1 n-5$ & 0.00 & 0.00 & 0.10 & 0.16 \\
\hline $16: 2$ & 0.28 & 0.62 & 0.36 & 0.35 \\
\hline 17:0 & 0.80 & 0.78 & 0.79 & 0.66 \\
\hline $17: 1$ & 0.76 & 0.61 & 0.80 & 0.69 \\
\hline $16: 4 n-1$ & 0.72 & 0.74 & 0.82 & 0.67 \\
\hline $16: 4 n-3$ & 0.33 & 0.44 & 0.48 & 0.40 \\
\hline $18: 0$ & 10.76 & 10.13 & 10.14 & 8.32 \\
\hline 18:1n-11 & 0.78 & 0.54 & 0.75 & 0.59 \\
\hline $18: \ln -9$ & 13.9 & 16.45 & 19.54 & 16.44 \\
\hline $18: 1 n-7$ & 4.83 & 4.82 & 5.86 & 5.27 \\
\hline $18: 2 n-9$ & 2.02 & 1.06 & 1.85 & 1.56 \\
\hline $18: 2 n-6$ & 4.57 & 3.57 & 3.17 & 1.77 \\
\hline $18: 3 n-9$ & 0.42 & 0.15 & 0.48 & 0.42 \\
\hline $18: 3 n-6$ & 0.32 & 0.00 & 0.12 & 0.18 \\
\hline $18: 4 n-6$ & 0.00 & 0.00 & 0.12 & 0.17 \\
\hline $18: 3 n-3$ & 1.01 & 0.16 & 0.00 & 0.19 \\
\hline $18: 4 n-3$ & 0.59 & 0.15 & 0.00 & 0.00 \\
\hline 20:0 & 0.28 & 0.25 & 0.13 & 0.17 \\
\hline $20.1 n-9$ & 1.32 & 2.10 & 1.85 & 1.50 \\
\hline $20: 1 n-7$ & 0.00 & 0.00 & 0.10 & 0.16 \\
\hline $20: 2 n-9$ & 0.00 & 0.00 & 0.08 & 0.00 \\
\hline $20: 2 n-6$ & 0.56 & 0.17 & 0.51 & 0.47 \\
\hline $20: 3 n-6$ & 0.00 & 0.00 & 0.10 & 0.20 \\
\hline $20: 4 n-6$ & 1.85 & 1.31 & 1.33 & 1.35 \\
\hline $20: 4 n-3$ & 2.04 & 0.00 & 0.21 & 0.32 \\
\hline $20: 5 n-3$ & 4.75 & 4.60 & 3.25 & 6.45 \\
\hline $22: 1 n-11$ & 0.41 & 0.80 & 0.66 & 0.36 \\
\hline $22: 1 n-9$ & 0.31 & 0.44 & 0.22 & 0.35 \\
\hline $22: 1 n-7$ & 0.28 & 0.13 & 0.16 & 0.20 \\
\hline $22: 4 n-6$ & 0.00 & 0.00 & 0.22 & 0.23 \\
\hline $22: 5 n-3$ & 1.18 & 0.79 & 0.59 & 1.21 \\
\hline $22: 6 n-3$ & 15.95 & 11.25 & 11.33 & 18.91 \\
\hline Saturates & 28.15 & 38.07 & 31.39 & 26.32 \\
\hline Monounsaturates & 30.22 & 32.75 & 37.82 & 32.99 \\
\hline n-9 & 18.72 & 20.66 & 24.32 & 20.53 \\
\hline$n-6$ & 7.30 & 5.05 & 5.56 & 4.37 \\
\hline$n-3$ & 25.85 & 17.47 & 15.98 & 27.65 \\
\hline n-3 HUFA & 23.92 & 16.63 & 15.37 & 26.89 \\
\hline DHA/EPA & 3.36 & 2.45 & 3.49 & 2.93 \\
\hline EPA/ARA & 2.57 & 3.51 & 2.44 & 4.78 \\
\hline Crude lipid ${ }^{\dagger}$ & 20.05 & 24.55 & 23.86 & 20.25 \\
\hline
\end{tabular}

$* \%$ total fatty acids, $n=3$.

${ }^{\dagger} \%$ in diet, $n=3$.

ARA, arachidonic acid; DHA, docosahexaenoic acid; EPA, eicosapentaenoic acid; HUFA, highly unsaturated fatty acids with 20 or more carbon atoms and three or more double bonds; SBL, soybean lecithin.

Increased dietary EPA in control diets improved larval stress resistance to handling and temperature shock, which could be related to its possible role as a regulator of cortisol production. Increase in dietary EPA and DHA has been found to increase stress resistance of juvenile gilthead sea bream by inhibition of the plasma cortisol levels induced by chronic, acute and repetitive stress. ${ }^{25}$ Besides, EPA, together with ARA and DHA, has been shown to regulate steroidogenesis in different hormone 
induced tissues of several species of fish and higher vertebrates. ${ }^{26,27}$ However, stress resistance after salinity shock was not improved by elevation of dietary EPA, as it has been also shown for Japanese flounder. ${ }^{22}$ This suggests that at the EPA dietary levels assayed, this fatty acid does not have an important role in osmoregulation. Indeed, in the gills, an important osmoregulatory tissue for fish, higher contents of ARA and lower EPA/DHA ratios are found in this (Liu et al., unpubl. data, 2001) and other species. ${ }^{28}$

Larvae fed the no SBL diet showed a lower lipid content characterized by a lower proportion of saturated and monounsaturated fatty acids than expected in comparison with their diet and the composition of the larvae on the control diet. In previous experiments with a similar type of diet for this fish species the analysis of the fatty acid composition of larval polar lipids showed that the depletion of $2 \%$ of the same type of soybean lecithin, reduces the incorporation of dietary ARA and DHA. ${ }^{29}$ These effects seemed to be related to the observed reduction in the appearance of lipoprotein particles in the lamina propria and demonstrated the critical reduction in the transport and utilization of dietary lipids, which in turn lead to lower growth and survival rates. Reduced growth and survival caused by low dietary lecithin levels is well-documented in the larvae of marine and freshwater fish species. ${ }^{4,30-34}$ Salhi et al found a high incidence of lipid vacuoles in the intestinal mucose of gilthead sea bream larvae fed diets containing low PL levels. This was not observed in the present experiment. ${ }^{5}$ That could be due to the higher PL lipid content derived from whole fat squid meal in the present experiment, this level being nevertheless insufficient to completely promote lipid transport and larval growth. Accumulation of lipid vacuoles has also been found in the enterocyte of PL deficient larval carp. ${ }^{35}$ The presence of some lipid vacuoles in the apical cytoplasm and the large size of lipoproteins observed in larvae fed the control diet could be correlated with the nature of dietary fatty acids, mainly with high dietary n-3 HUFA levels. In this sense, Sire and Vernier found large lipid droplets and chylomicrons associated with a high proportion of dietary n-3 polyunsaturated fatty acids. ${ }^{36}$

The fact that growth was more clearly reduced in these larvae between day 18 and 26 confirms that soybean lecithin, namely dietary PL levels, are more important in younger larvae, as it was shown by Koven etal. ${ }^{37}$ This age-dependant effect of soybean lecithin could also explain that the stress resistance of the larvae was not affected by the dietary soybean lecithin content, despite the fact that increased dietary lecithin levels have been found to improve stress resistance in this and other species. $^{5,29}$

The results of this study have shown that even when dietary DHA levels are high enough (4.96\%) to cover the larval requirements for DHA and dietary ARA levels are about $0.2 \%$, EPA is necessary to improve larval growth, survival and resistance to stress. It was demonstrated that dietary soybean lecithin markedly increases the appearance of lipoproteins in larval gut, enhancing lipid transport and promoting growth and survival in gilthead sea bream.

\section{ACKNOWLEDGMENTS}

The authors thank Nippon Chemical Company for supplying the experimental oils. Acknowledgment is also due to Agencia Española de Cooperación Internacional (AECI) and Instituto Agronómico del Mediterráneo de Zaragoza (CIHEAM) for financially supporting this study by grants to Jingle Liu and Tamer El-Sayed, respectively.

\section{REFERENCES}

1. Watanabe T, Kitajima C, Fujita S. Nutritional value of live organisms used in Japan for mass propagation of fish: a review. Aquaculture 1983; 34: 115-143.

2. Kanazawa A. Importance of DHA in organisms. Pros. Puslibangkan 1993; 18: 62-70.

3. Fontagné S. Effet des phospholipides alimentaires sur la structure histologique du foie et de l'intestin de larves de carpe. Disertation Thesis. University Bordeaux, Bordeaux, France, 1996.

4. Izquierdo MS, Socorro J, Arantzamendi L, Hernández-Cruz CM. Recent advances in lipid nutrition in fish larvae. Fish Physiol. Biochem. 2000; 22: 97-107.

5. Salhi M, Hernandez-Cruz CM, Bessonart M, Izquierdo MS, Fernandez-Palacios H. Effect of different dietary polar lipid levels and different n-3 HUFA content in polar lipids on gut and liver histological structure of gilthead seabream (Sparus aurata) Aquaculture 1999; 179: 253-263.

6. Kanazawa A, Teshima S, Sakamoto M. Effects of dietary bonito-egg phospholipids and some phospholipids on growth and survival of the larval ayu, Plecoglossus altivelis. Z. Angew. Ichthyol. 1985; 4: 165-170.

7. Teshima S, Kanazawa A, Horinouchi K, Yamashita S, Hirata H. Phospholipids of the rotifers, prawn and larval fish. Nippon Suisan Gakkaishi 1987; 53: 609-615.

8. Izquierdo MS, Tandler A, Salhi M, Kolkovsky S. Incorporation of radiolabelled free fatty acids, triglicerides and phospholipids into larval gilthead seabream (Sparus aurata) lipids. Aquacult. Nutr. 2001; 7 (3): 153-160.

9. Watanabe T, Izquierdo MS, Takeuchi T. Satoh S, Kitajima C. Comparison between eicosapentaneoic and docosahexaenoic acids in terms of essential fatty acids efficacy in larval red seabream. Nippon Suisan Gakkaishi 1989; 55 (9): 1635-1640. 
10. Takeuchi T, Arakawa T, Satoh S, Watanabe T. Supplemental effect of phospholipids and requirement of eicosapentaenoic acid and docosahexaenoic acid of juvenile striped jack. Nippon Suisan Gakkaishi 1992; 58 (4): 707-713.

11. Izquierdo MS. Essential fatty acids requirements of cultured marine fish larvae. Aquacult. Nutr. 1996; 2: 183-191.

12. Sargent JR, McEvoy LA, Bell JG. Requirements, presentation and sources of polyunsaturated fatty acids in marine fish larval feeds. Aquaculture 1997; 155: 117-127.

13. Rodríguez C, Pérez JA, Lorenzo A, Izquierdo MS, Cejas JR. N-3 HUFA requirement of larval gilthead seabream (Sparus aurata) when using high levels of eicosapentaenoic acid. Comp. Biochem. Physiol 1994, 107a: 693-698.

14. Kitajima C, Arakawa T, Oowa G, Fujita S, Imada O, Watanabe T, Yone Y. Dietary value for red seabream of rotifer, Brachionus plicatilis, cultured with a new type of yeast. Nippon Suisan Gakkaishi 1980; 46: 43-46.

15. Rodríguez C. Estudio de los requerimientos de ácidos grasos esenciales de la dorada europea (Sparus aurata, L.) durante las primeras semanas de alimentación. $\mathrm{PhD}$ Thesis. Universidad de La Laguna, Spain, 1994.

16. AOAC. Official Methods of Analysis, 14th edn. Association of Analytical Chemists, Washington. 1985, 1018.

17. Folch J, Lees M, Stanley GHS. A simple method for the isolation and purification of total lipids from animal tissues. J. Biol. Chem. 1957; 226: 497-509.

18. Christie WW. Gas Chromatography and Lipids: a Practical Guide. The Oily Press, Ayr. 1989, 67-69.

19. Izquierdo MS, Watanabe T, Takeuchi T, Arakawa T, Kitajima C. Optimum EFA levels in Artemia to meet the EFA requirements of red sea bream (Pagrus major). In: Takeda M, Watanabe T (eds). The Current Status of Fish Nutrition in Aquaculture. Tokyo University Fisheries, Tokyo. 1990, 221-232.

20. Furuita H, Takeuchi T, Uemasu K. Effects of eicosapentaenoic and docosahexaenoic acids on growth, survival and brain development of larval Japanese flounder (Paralichthys olivaceous). Aquaculture 1998; 161: 269-279.

21. Furuita H, Takeuchi T, Watanabe T, Fujimoto H, Sekiya S, Imaizumi K. Requirements for larval yellowtail for eicosapentaenoic, docosahexaenoic and n-3 highly unsaturated fatty acids. Fish. Sci. 1996; 62: 372-379.

22. Furuita H, Kooichi K, Takeuchi T. Effect of different levels of eicosapentaenoic acid and docosahexaenoic acid in Artemia nauplii on growth, survival and salinity tolerance of larvae of the Japanese flounder, Paralycthis olivaceous. Aquaculture 1999; 170: 59-69.

23. Jahangiri A, Leifert WR, Patten GS, McMurchie J. Termination of asynchronous contractile activity in rat atrial myocytes by n-3 polyunsaturated fatty acids. J. Mol. Cell. Biochem. 2000; 206: 33-41.

24. Roo FJ, Izquierdo MS, Socorro J, Hernandez-Cruz CM, Valencia A, Fernández-Palacios H. Importance of dietary n-3 HUFA for eye development and cone formation in gilthead seabream (Sparus aurata) larvae. Fish. Sci. 2002; in press.

25. Montero D, Tort L, Izquierdo MS, Robaina L, Vergara JM. Depletion of serum alternative complement pathway activity in gilthead seabream caused by alpha-tocopherol and n-3 HUFA dietary deficiencies. Fish Physiol. Biochem. 1998; 18 (4): 399-407.

26. Wang X, Stocco DM. Cyclic AMP and arachidonic acid: a tale of two pathways. Mol. Cell. Endocrinol. 1999; 158: 7-12.

27. Asturiano JF, Sorbera LA, Zanuy S, Carrillo M. Effect of polyunsaturated fatty acids and gonadotropin prostaglandine series $\mathrm{E}$ production in a primary testis cell culture system for European sea bass. J. Fish. Biol. 2000; 57: 1563-1574.

28. El-Sayed Ali T, Robaina L, Jover Cerdá M, García A, Izquierdo MS. Effect of dietary lipid sources on fatty acid composition of different tissues in yellowtail (Seriola dumerilii). Bull. Institute Esp. Ocean. 2002; in press.

29. Salhi M, Kolkovski S, Izquierdo M, Tandler A. Inclusion of lecithin and polar or neutral lipids high in n-3 HUFA in microdiets for gilthead seabream Sparus aurata larvae. European Aquaculture Society, Special Publication, 1995; 24: 184-187.

30. Kanazawa A. Effects of docosahexaenoic acid and phospholipids on stress tolerance of fish. Aquaculture 1997; 155: 129-134.

31. Craig SR, Gatlin DM. Growth and body composition of juvenile red drum (Sciaenops ocellatus) fed diets containing lecithin supplemental choline. Aquaculture 1997; 151: 259-267.

32. Geurden I, Charlon N, Marion D, Bergot P. Influence of purified soybean phospholipids on early development of common carp. Aquacult. Int. 1997; 5: 137-149.

33. Paul BN, Nandi S, Sarkar S, Mukhopadhyay PK. Dietary essentiality of phospholipids in Indian major carp larvae. Asian Fish Sci. 1998; 11: 253-259.

34. Koven W, Barr Y, Lutzky S, Ben-Atia I, Weiss R., Harel M, Behrens P, Tandler A. The effect of dietary arachidonic acid (20. $4 \mathrm{n}-6)$ on growth, survival and stress resistance to handling stress in gilthead seabream (Sparus aurata) larvae. Aquaculture 2001, 193: 107-122.

35. Fontagné S, Guerden I, Escaffre AM, Bergot P. Histological changes induced by dietary phospholipids in intestine and liver of common carp (Cyprinus carpio L.) larvae. Aquaculture 1998; 161: 213-223.

36. Sire MF, Vernier JM. Étude ultrastructurale de la synthèse de chylomicrons au cours de l'absorption intestinale des lipides chez la Truite. Influence de la nature des acides gras ingérés. Biol. Cell 1981; 40: 47-62.

37. Koven WM, Kolkovski S, Tandler A, Kissil GWm, Sklan D. The effect of dietary lecithin and lipase as a function of age, on n-9 fatty acid incorporation in the tissue lipids Sparus aurata larvae. Fish Physiol. Biochem. 1993; 10: 357-364.

38. Kanazawa A, Koshio S, Teshima S. Growth and survival of larval red seabream (Pagrus major) and Japanese Flounder (Paralichthys olivaceous) fed microbound diets. J. World Aquaculture Soc. 1989; 20: 31-37.

39. Kanazawa A. Essential fatty acid and lipid requirement of fish. In: Cowey CB, Mackie AM, Bell JG (eds). Nutrition and Feeding in Fish. Academic Press, London. 1985, 287-298.

40. Teshima S, Kanazawa A, Sakamoto S. Microparticulate diets for the larvae of aquatic animals. Min. Rev. Data File Fish. Res. 1982; 2: 67-86. 